Radmilo D. Markovic

$$
\begin{gathered}
\text { Civil Engineering Department } \\
\text { Colorado State University } \\
\text { Fort Collins, Colorado } \\
\text { July, } 1966
\end{gathered}
$$


Property of Civil Engineering

Dept. Foothills Reading Room

Received: 22 AuGuST 1966

U18401 0574441 
CONTROL LEVELS FOR QUANTITATIVE EVALUATION OF

WEATHER MODIFICATION ATTAINMENTS

By

Radmilo D. Markovic

Civil Engineering Department

Colorado State University

Fort Collins, Colorado

For presentation at

The Sixth Western National Meeting

Section of Hydrology, American Geophysical Union

Los Angeles, September 7-9, 1966 


\title{
CONTROL LEVELS FOR QUANTITATIVE EVALUATION OF \\ WEATHER MODIFICATION ATTAINMENTS*
}

\author{
By \\ Radmilo D. Markovic \\ Civil Engineering Department, Colorado State University \\ Fort Collins, Colorado
}

\section{INTRODUCTION}

Weather modification or cloud seeding evaluation studies undertaken in the past consisted of two major programs, qualitative and quantitative. The qualitative or physical evaluation program was designed to learn what took place in a cloud system during artificial treatments and to study the meteorological conditions which determined under what circumstances could these treatments produce the most desirable results [1].

The quantitative or statistical evaluation program, based upon mathematical and statistical analysis of data from many seedings was conducted in order to determine if these operations had actually produced an identifiable increase in precipitation [2].

The subject of this paper is to consider all possible levels of weather modification control at which the quantitative evaluation can take place, to analyze their properties, and to indicate the most promising, feasible and detectable level of control.

There are three basic control levels at which the quantitative evaluation of weather modification (cloud seeding) attainments can take place. These are: cloud phenomena, precipitation and river flow control levels, which correspond to three particular stages in the general hydrologic cycle [3].

\section{CLOUD PHENOMENA CONTROL LEVEL}

This is the level in the atmosphere or in a cloud system, the other two control levels refer to the ground, Fig. 1. Since this level is in the atmosphere, it has to deal with the air as a fluid, the determination of its motion, state and forces when it is subjected to a specific

\footnotetext{
*This paper is primarily based on research done at Colorado State University for the U. S. Bureau of Reclamation, Contract No. 14-06-D-5299, Mathematical methods of evaluation of results of atmospheric water resources programs.
} 


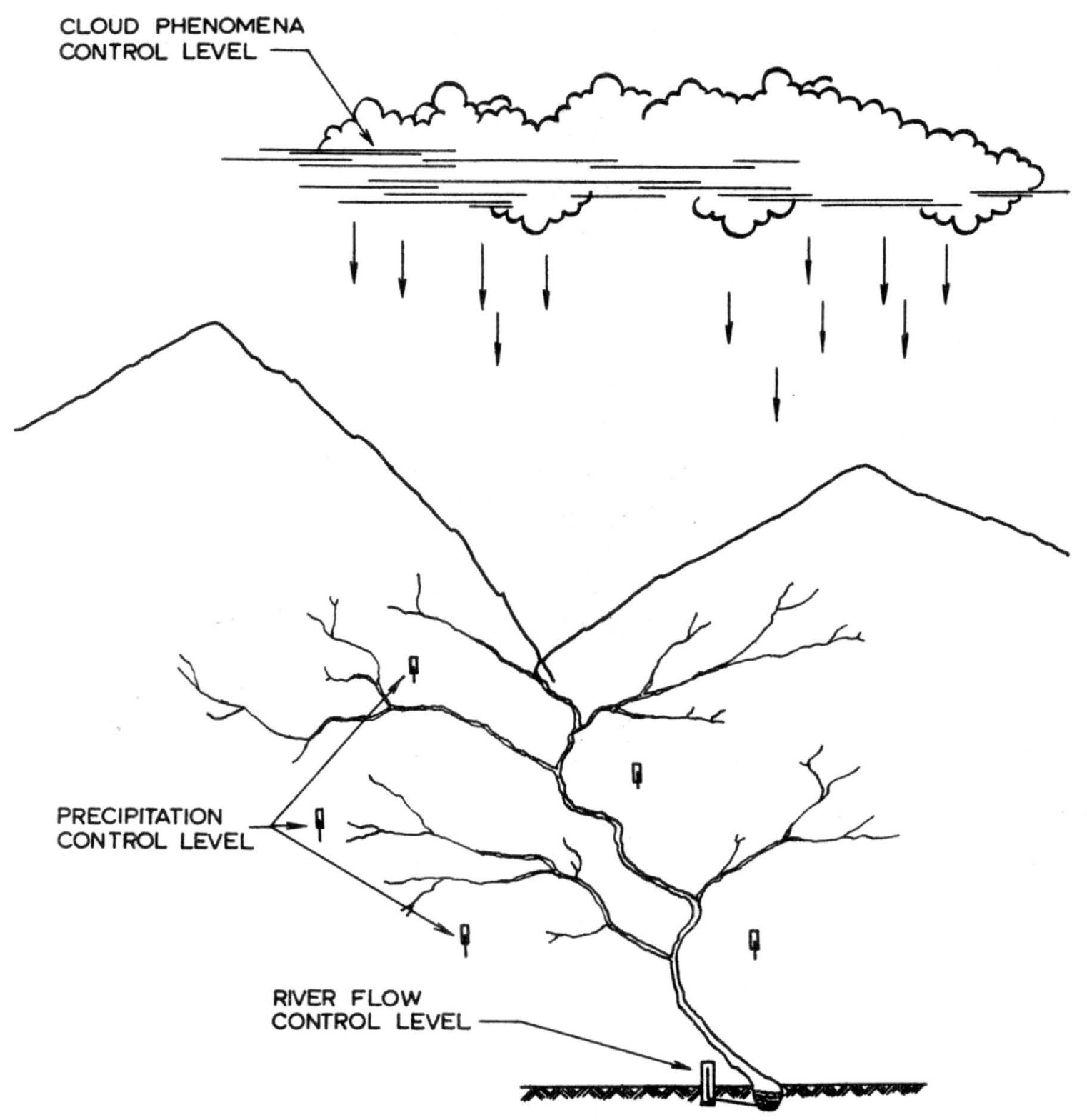

Fig. I Schematic representation of control levels for quantitative evaluation of weather modification attainments 
force system and boundary conditions - geometry, surface conditions and field conditions. Any property of air, such as temperature, density, viscosity, pressure, compressibility, velocity, acceleration, internal stresses, and rate of deformation varies with space and time. These properties and their interactions are important for cloud formations and further processes in the cloud which lead to precipitation, and therefore, they must be studied. In addition, some bulk properties such as moisture, cloud dimensions and structure, winds, storm movement, rate of storm growth, number and size and size distribution of nuclei must be measured and studied too. To measure these important properties, radar facility, aircrafts, kites, mobile ground units, which are a part of the total communications network, should be used to collect data which add to a better understanding of a storm mechanism over a studied area. Large funds, time and intensive efforts have to be invested in the collection of such data. Even if it was done for cloud systems treated by cloud seeding, there is no sufficient number of measurements of natural clouds to compare them with artificially seeded storms. This is particularly true regarding high variability of cloud properties. A study of a large number of precipitation clouds by radar has discovered marked day-to-day variations of all cloud parameters [4].

However, even if the comparison of nonseeded and seeded clouds is possible, the problem of evaluating the effect, if any, of artificial seeding on augmentation of precipitation reaching the ground would still remain. It is obvious, therefore, that some additional relations to ground control levels are needed in order to evaluate any change due to the seeding. For this reason, the cloud phenomena control level is not self-sufficient. It is also not a convenient and reliable level for quantitative evaluation of weather modification. Because of these properties, this level has been predominantly used for qualitative rather than for quantitative evaluation of cloud seeding operations.

3. PRECIPITATION CONTROL LEVEL

The level of control is on the ground, at the network of precipitation stations, Fig. 1. It is represented by that portion of the total amount of precipitation which reached the ground and was measured or recorded at the existing network of raingage stations. 
This level has the advantage of being on the ground and dealing with precipitation fallen on the ground, part of which man can utilize for his needs. Its further advantage manifests of being the part of existing collection of precipitation data observed for many years at many raingage stations. This collection of historical data reflecting the natural, untreated conditions at particular localities, represents an excellent base for evaluation purposes at localities where new or treated conditions are taking place. These advantages have been the main reason why this level of control has been predominantly used in evaluating the weather modification attainments in the past.

Besides these advantages, the fact that precipitation data is used in evaluating process implies several disadvantages. These are mainly caused by the inaccuracy of precipitation measurements and the unreliability of estimating the mean areal precipitation.

Observed precipitation data is subject to measurement error because of the difficulty of accurately gaging precipitation. The main cause for inaccuracy is the wind which tends to carry the rain over and past the gage. Nearby obstacles may intercept or deflect the wind-swept rain, reducing the accuracy of the gage. Because of greater exposure to the wind, hillcrest locations give poor accuracy. Gages on rooftops usually show less rain than those on posts, and post gages show less than ground level gages. The error in rain gage catch varies with the height above the ground. As a result, the gaged rain is often 5 or 10 percent low and may be 50 percent low in strong winds [5]. This deficiency may be as much as 60 percent for true snowfall in winds of $30 \mathrm{mph}$ at the orifice level. Equipping gages with windshields increases the catch approximately 20 percent in open areas and by about 10 percent in forest glades [6].

The error of determining the mean areal precipitation is the source of further disadvantage of this control level. The areal precipitation is estimated from the point measurements taken from gaged precipitations. The error involved in this estimation depends on the accuracy and density of these point measurements. When the density is considered, it has been shown that the absolute error caused by an inadequate density of precipitation gages increases with an increase in the amount of precipitation and with the gaging ratio (area per gage) in dealing with storm totals [7]. 
The error markedly decreases, however, when averages for longer periods are considered [8], because the areal variation of precipitation decreases with an increase of these periods. To illustrate this error, one actual example will be presented. For this purpose the average annual precipitation over the Kings River Watershed above Piedra, California for the 1951-1964 water year period was selected. From this and surrounding areas, data from 11 gage sites were chosen, Fig. 2, for estimation of the 14 year mean annual precipitation over a 1687 square mile area. The estimated value was computed by the Thiessen method [6], which gives weight to the areal distributions of stations. The name of stations, their positions-longitude, latitude and elevation - as well as the percentage of total area they represent, are given in Table 1.

The annual station precipitation, $P_{j i}$ in inches per year for $j$ station in $i$ year, are presented in Table 2. The annual weighted areal precipitation, $p_{j i}$, in inches per year over area, $a_{j}$, for $j$ station in $i$ year, are computed by

$$
p_{j i}=P_{j i} \cdot a_{j}
$$

The annual precipitation over the whole Kings River Watershed above Piedra are obtained from

$$
P_{i}=\sum_{j=1}^{11} p_{j i}=\sum_{j=1}^{11} P_{j i} \cdot a_{j} \cdot
$$

Both the individual and overall annual areal precipitation are presented in Table 3. As shown in this table, the average annual precipitation over the entire watershed for the 14 year period is 34.99 inches per year. This value is considered to be the best estimate of the average in this particular case, since its computation is based on the maximum number of available precipitation stations in the area. However, if fewer stations were available, the estimate of average annual precipitation over the whole watershed for the same 14 year period, computed simply as their arithmetic mean, would be somewhat different. 


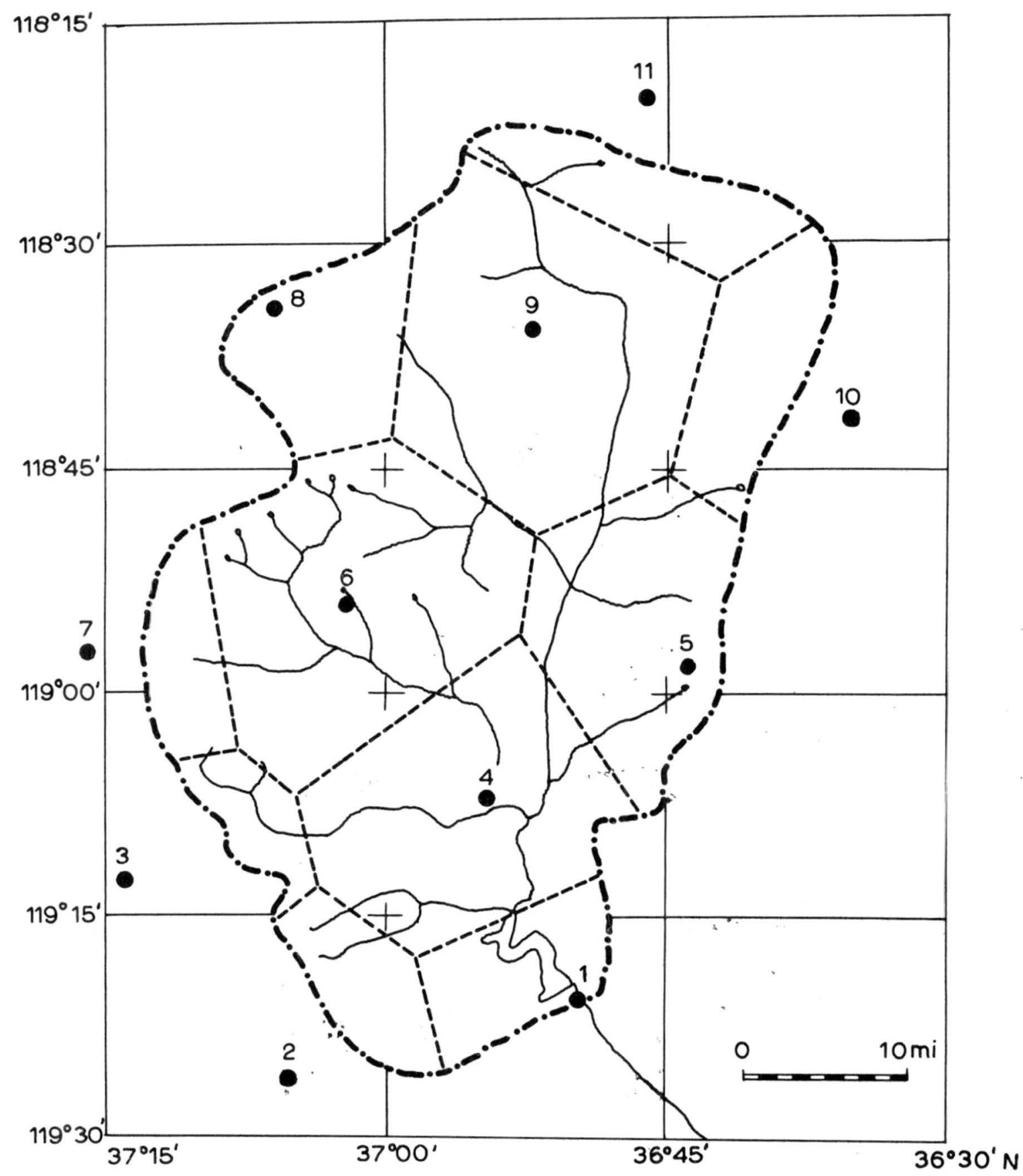

Fig. 2 Network of precipitation stations in the Kings River Watershed above Piedra, California. 
Table 1. Precipitation stations in the Kings River Watershed above Piedra, California

\begin{tabular}{|c|c|c|c|c|c|}
\hline j & Name & $\begin{array}{l}\text { Long } \\
\text { (deg.min) }\end{array}$ & $\begin{array}{l}\text { Lat. } \\
\text { (deg.min) }\end{array}$ & $\begin{array}{l}\text { Elev. } \\
\text { (ft.) }\end{array}$ & $\begin{array}{r}\text { Area } \\
a_{j}(\%)\end{array}$ \\
\hline 1. & Piedra & $119^{\circ} 23^{\prime}$ & $36^{\circ} 48^{\prime}$ & 580 & 5.5 \\
\hline 2. & Meadow Lake & $119^{\circ} 26^{\prime}$ & $37^{\circ} 05^{\prime}$ & 4485 & 3.8 \\
\hline 3. & Huntington Lake & $119^{\circ} 13^{\prime}$ & $37^{\circ} 14^{\prime}$ & 7020 & 2.9 \\
\hline & Balch Power House & $119^{\circ} 06^{\prime}$ & $36^{\circ} 54^{\prime}$ & 1750 & 14.7 \\
\hline 5. & Grant Grove & $118^{\circ} 58^{\prime}$ & $36^{\circ} 44^{\prime}$ & 6580 & 10.9 \\
\hline 6. & Woodchuck Meadow & $118^{\circ} 54^{\prime}$ & $37^{\circ} 02^{\prime}$ & 9200 & 18.8 \\
\hline 7. & Florence Lake & $118^{\circ} 58^{\prime}$ & $37^{\circ} 16^{\prime}$ & 7355 & 3.3 \\
\hline 8. & Bishop Pass Snow Course & $118^{\circ} 34^{\prime}$ & $37^{\circ} 06^{\prime}$ & 11040 & 7.1 \\
\hline 9. & Granite Basin & $118^{\circ} 36^{\prime}$ & $36^{\circ} 52^{\prime}$ & 10000 & 20.7 \\
\hline 10. & Giant Forest & $118^{\circ} 46^{\prime}$ & $36^{\circ} 34^{\prime}$ & 6360 & 6.8 \\
\hline \multirow[t]{2}{*}{11.} & Independence Onion Valley & $118^{\circ} 20^{\prime}$ & $36^{\circ} 46^{\prime}$ & 9175 & 5.5 \\
\hline & & & & & 100.0 \\
\hline
\end{tabular}

To illustrate these differences, several possible combinations of stations are applied to compute the estimate of a 14 year areal average, $\bar{P}(\cdots)$ with numbers in the parentheses indicating the order numbers of stations used:

$$
\begin{aligned}
& \bar{P}(1,2,3, \ldots, 11)=34.99 \mathrm{in} / \mathrm{yr} . \quad \bar{P}(4,5,9)=36.92 \mathrm{in} / \mathrm{yr} . \\
& \bar{P}(4,5,6,8,9) \quad=35.61 \mathrm{in} / \mathrm{yr} . \quad \bar{P}(4,6,9)=37.15 \mathrm{in} / \mathrm{yr} . \\
& \overline{\mathrm{P}}(4,5,6,8) \quad=34.52 \mathrm{in} / \mathrm{yr} . \overline{\mathrm{P}}(4,9)=34.20 \mathrm{in} / \mathrm{yr} . \\
& \overline{\mathrm{P}}(4,5,6,9) \quad=38.45 \mathrm{in} / \mathrm{yr} . \quad \overline{\mathrm{P}}(5,6)=42.69 \mathrm{in} / \mathrm{yr} .
\end{aligned}
$$

The variability of results is obvious. The density of stations, though inadequate for such a watershed size, is not solely responsible for the instability of the estimate of average areal precipitation. The areal and elevation distribution of stations are also contributive factors. The accuracy of the estimate of areal precipitation in a watershed is, therefore, 
Table 2. Annual station precipitation in the Kings River Watershed above Piedra, California

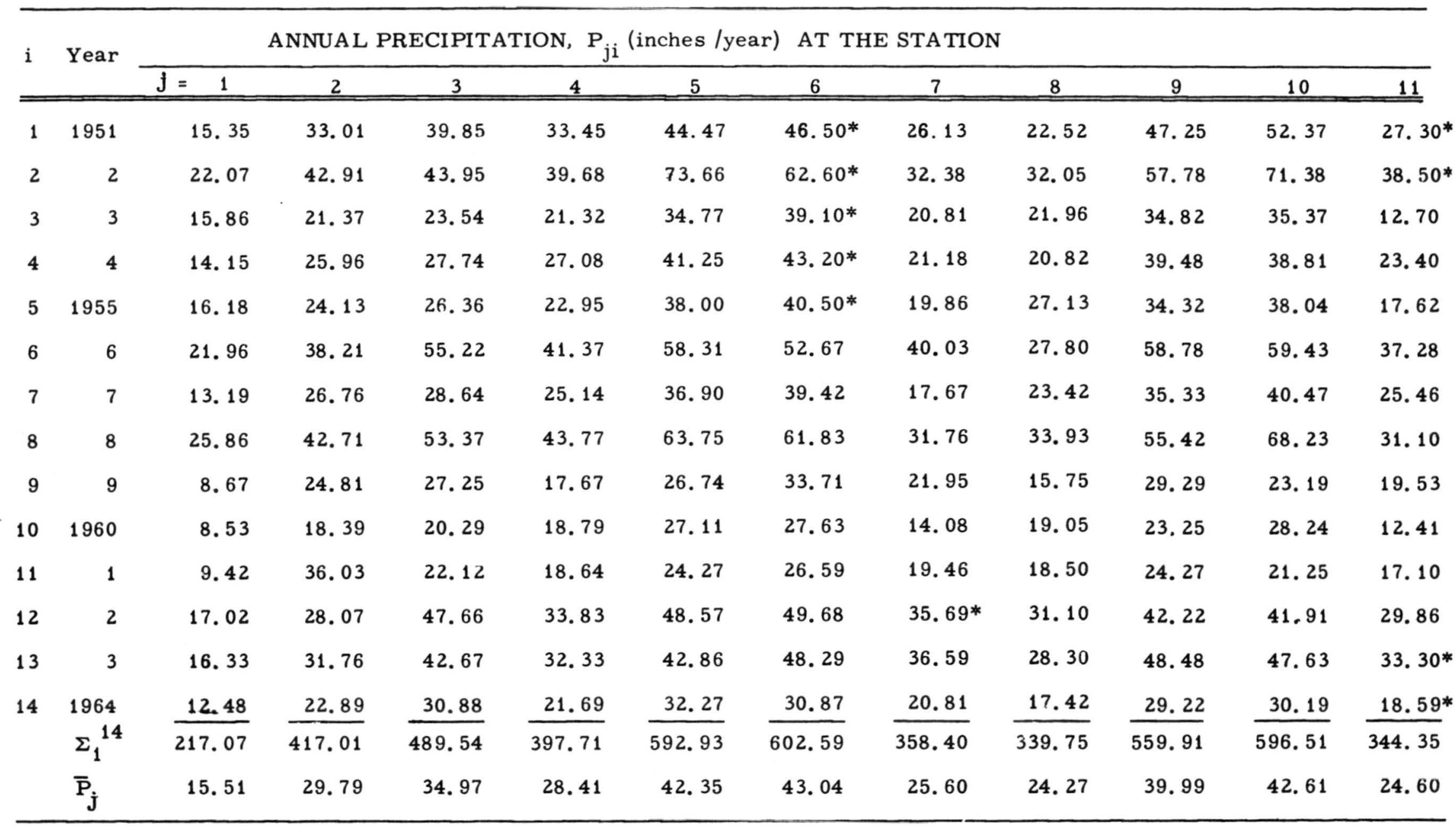

* Missing data from 1 to 12 months filled out by data from nearby stations. 
Table 3. Annual weighted areal precipitation in the Kings River Watershed above Piedra, California

\begin{tabular}{|c|c|c|c|c|c|c|c|c|c|c|c|c|c|}
\hline \multirow{2}{*}{$\mathrm{i}$} & \multirow{2}{*}{ Year } & \multicolumn{7}{|c|}{ ANNUAL WEIGHTED AREAL PRECIPITATION, } & \multicolumn{4}{|c|}{$=P_{j i} a_{j}$ (inches $/$ year $)$} & \multirow{2}{*}{$P_{i}=\sum_{1}^{11} p_{j}$} \\
\hline & & $\mathbf{j}=1$ & 2 & 3 & 4 & 5 & 6 & 7 & 8 & 9 & 10 & 11 & \\
\hline 1 & 1951 & 0.84 & 1. 26 & 1.15 & 4.92 & 4.85 & 8.75 & 0.86 & 1.60 & 9.78 & 3.56 & 1.50 & 39.07 \\
\hline 2 & 2 & 1.25 & 1.63 & 1.27 & 5.84 & 8.04 & 11.75 & 1.07 & 2.28 & 11.96 & 4.85 & 2.12 & 52.06 \\
\hline 3 & 3 & 0.87 & 0.81 & 0.68 & 3. 14 & 3. 79 & 7.35 & 0.69 & 1.56 & 7.21 & 2.40 & 0.70 & 29.20 \\
\hline 4 & 4 & 0.78 & 0.99 & 0.80 & 3.98 & 4.50 & 8.13 & 0.70 & 1.48 & 8.18 & 2. 64 & 1. 29 & 33.47 \\
\hline 5 & 1955 & 0.89 & 0.92 & 0.76 & 3.37 & 4.14 & 7.62 & 0.66 & 1.92 & 7.11 & 2. 59 & 0.97 & 30.95 \\
\hline 6 & 6 & 1.21 & 1.45 & 1.60 & 6.08 & 6.36 & 9.90 & 1. 32 & 1.97 & 12. 18 & 4.04 & 2.05 & 48. 16 \\
\hline 7 & 7 & 0.72 & 1.02 & 0.83 & 3. 70 & 4.02 & 7.42 & 0.58 & 1.66 & 7. 32 & 2. 75 & 1.40 & 31.42 \\
\hline 8 & 8 & 1.42 & 1.62 & 1.55 & 6.45 & 6.95 & 11.62 & 1.05 & 2.41 & 11.46 & 4. 64 & 1.72 & 50.89 \\
\hline 9 & 9 & 0.48 & 0.94 & 0.79 & 2.60 & 2. 92 & 6.34 & 0.73 & 1.12 & 6.07 & 1.57 & 1.08 & 24.64 \\
\hline 10 & 1960 & 0.47 & 0.70 & 0.59 & 2. 76 & 2. 96 & 5.20 & 0.46 & 1. 35 & 4.83 & 1.92 & 0.68 & 21.92 \\
\hline 11 & 1 & 0.52 & 1. 37 & 0.64 & 2. 74 & 2. 64 & 5.00 & 0.64 & 1. 31 & 5.03 & 1.44 & 0.94 & 22. 28 \\
\hline 12 & 2 & 0.94 & 1.06 & 1. 38 & 4. 98 & 5.30 & 9. 34 & 1. 18 & 2. 21 & 8.75 & 2.85 & 1.64 & 39.63 \\
\hline 13 & 3 & 0.90 & 1.21 & 1. 24 & 4.75 & 4.67 & 9.08 & 1.21 & 2.01 & 10.03 & 3. 24 & 1.83 & 40.17 \\
\hline \multirow[t]{3}{*}{14} & 1964 & 0.69 & 0.87 & 0.90 & 3. 19 & 3.52 & 5.80 & 0.69 & 1. 24 & 6.06 & 2. 05 & 1.02 & 26.03 \\
\hline & $\Sigma_{1}^{14}$ & 11. 98 & 15.85 & 14. 18 & 58.50 & 64.67 & 113.30 & 11.84 & 24.12 & 115.97 & 40.54 & 18. 94 & 489.89 \\
\hline & $\bar{p}_{j}$ & 0.86 & 1.13 & 1.01 & 4.18 & 4.62 & 8.09 & 0.85 & 1.72 & 8.28 & 2. 90 & 1. 35 & 34.99 \\
\hline
\end{tabular}


a function of the accuracy of single measurements, the adequacy of density of precipitation stations, and the uniformity of areal and elevation distribution of stations.

Referring to the problem of evaluating weather modification when the target-control concept is used, the same problem of accuracy and reliability of precipitation data exists equally in both target and control areas. However, when these two different accuracies are coupled in an evaluation process, the resulting effect might be either negligible or very significant. It might show an "evident" change where it did not exist or "mask" a change where it did exist. This effect is obviously uncertain.

The above examples indicate that the precipitation control level as presently used, is not an accurate or reliable level of control as far as the quantitative evaluation of weather modification is concerned. The main reasons are large single measurements and large areal sampling errors involved. Some of the reasons mentioned above were probably partially responsible for various and often contradictory conclusions about cloud seeding effects in the past. The future of this control level depends on the progress in decreasing substantially the above two types or errors.

\section{RIVER FLOW CONTROL LEVEL}

Weather modification attainments, if any, are controlled at the network of river gaging stations, Fig. 1. This level of control is on the ground and is represented either by flow rate (discharge) or by volume of flow drained from an area.

The principal advantage of this control level, besides that of being on the ground, lies in the fact that it directly deals with water man can use for its needs. The water produced out of a river basin is the main goal and the final product of the majority of weather modification projects that were undertaken in the past. Thus, this control level measures directly the availability of water resources for man's use.

Another important advantage of this level manifests itself in the property of river flow of being an integrated representative of the whole area under consideration. The discharge is not a point-measurement in the space, but rather an integrated measurement of the entire area above the gage site. If a watershed is considered as a catching area of moisture from the atmosphere, then the river flow measured at the outlet 
of such an area represents the total water collected at that watershed. The river flow measures at the same time, the yield of the watershed and its capability as a source of water supply.

The main disadvantages of this control level are: (a) the inaccuracy of discharge measurement; (b) the relatively high variability of natural river flows; and (c) the time dependence of successive river flows due to carryover effect. The accuracy of discharge measurement depends mainly on the local physical conditions of gage site, the type and adequacy of the stage-measuring equipment and the frequency of measurements. Very low flows at gaging stations, lacking a permanent and well defined control, may be subject to a high percentage error because of the difficulties to measure these flows during dangerous flood conditions. Flow rates or volumes accumulated over long periods, a year for example, are more reliable than those for short periods because of the possibility for compensation of errors [6].

According to the U. S. Geological Survey classification regarding its measurements and published records, the accuracy of single discharge measurements is within 2 percent for excellent and within 5 percent for good measurements. The probable error of published river flow records is estimated to be between less than 5 to 10 percent [6]. The excellent and good river flow data are supposed to be used exclusively for evaluation purposes of weather modification. As it can be seen, the relative probable errors of individual measurements are not as small as would be desired, but they are still within tolerable limits. However, these errors decrease rapidly with the increase of time units over which the river flows are averaged.

Significant errors may be encountered when dealing with differences in river flow between two watersheds. This is because of the opportunity of combining the errors which may be of opposite sign. Diversion for irrigation or water supply, pumping of ground water, storage in reservoirs and natural lakes may present problems because the data may not be homogeneous in time. However, the uncertainty of these types of errors can be considerably reduced by proper analysis of data, adequate selection of river flow records and by detailed analysis of station and river basin history, and field notes of the hydrographer maintaining the station in question. 
Considering the variability of river flow, it greatly affects the evaluation process. For a large variability, long historical records and periods of cloud seeding experiments are required to detect any change caused by the weather modification. Little can be done to avoid this, since the variability of river flow is practically the reflection of the variability of natural factors producing and affecting runoff. Nevertheless, some speculations are still possible through statistical evaluation by proper selection of variable and time over which it is averaged, as well as the sample size of records.

The time dependence of successive river flows due to the carryover effect, implies the use of large time units (season, year) for the flow variable used in an evaluation process. This can represent a disadvantage in some cases.

The river flow control level, though not ideal, can be valuable in quantitative evaluation of weather modification. For unexplainable reasons, it has not been used extensively for evaluation purposes in the past.

\section{COMPARISON OF CONTROL LEVELS}

According to the properties of control levels described earlier, it can be seen that not all the control levels are equally suitable for quantitative evaluation of weather modification experiments. The lack of sufficient and reliable data at the cloud phenomena control level makes its use less feasible for evaluation purposes at the present time. Its use has also to be coupled with one of the ground control levels. The choice is thus limited to one or two other levels which should be closely analyzed and compared.

The precipitation control level deals with the total precipitation fallen on the ground, part of which becomes useful water, while the river flow control level directly measures the available water for man's use. The precipitation measurements represent the point measurements in an area, while the river flow measurements represent the integrated measure of whole water drained from an area above the gage site. The accuracy of a single precipitation measurement is in general inferior to the accuracy of a single discharge measurement, particularly in areas where snow is the predominante type of precipitation. The estimate of mean areal precipitation 
is usually unreliable and represents the most serious disadvantage of the precipitation control level.

Certain statistical properties of precipitation and river flow, which are very important in the process of quantitative evaluation, also deserve attention. The most useful and applied statistics are the mean, variance and coefficient of variation. The precipitation mean, as a rule, is greater than the river flow mean when expressed in the same units and over the same area. The absolute value of variance is generally higher for precipitation than for river flow, while the variability as expressed in the coefficient of variation is usually lower for precipitation than for river flow. These statements are very well illustrated in the example of the Kings River Watershed above Piedra. These three statistics, the mean areal precipitation, $\bar{P}$, the variance, $s^{2}$, and the coefficient of variation, $C_{v}$, are computed for 14 water years 1951-1964, as

$$
\begin{aligned}
& \bar{P}=\frac{1}{14} \sum_{i=1}^{14} P_{i}=\frac{1}{14} 489.89=34.99 \mathrm{in} . / \mathrm{yr} . \\
& \left.s^{2}=\frac{1}{14} \sum_{i=1}^{14}\left(P_{i}-\bar{P}\right)^{2}=\frac{1}{14} 1367.30=97.66 \text { (in./yr. }\right)^{2} \\
& C_{v}=\frac{s}{\bar{P}}=\frac{\sqrt{97.66}}{34.99}=0.282 .
\end{aligned}
$$

Similarly, the same statistics are computed for river flow, $S_{j}$, which are first derived from the annual runoff, $R_{j}$, in acre-feet per year, by converting them into inches per year over the watershed area of 1687 square miles:

$$
\begin{aligned}
& S_{i}=\frac{12 R_{i}}{1687 \times 640}, \\
& \bar{s}=\frac{1}{14} \sum_{i=1}^{14} S_{i}=\frac{1}{14} 238.20=17.01 \mathrm{in} . / \mathrm{yr} . \\
& s^{2}=\frac{1}{14} \sum_{1}^{14}\left(S_{i}-\bar{s}\right)^{2}=\frac{1}{14} 922.13=65.87(\text { in. } / \mathrm{yr} .)^{2}
\end{aligned}
$$




$$
C_{v}=\frac{s}{\bar{s}}=\frac{\sqrt{65.87}}{17.01}=0.477 .
$$

The higher the mean, the smaller the variance and the coefficient of variation, the better it is to discriminate any change in precipiation or river flow mean. The above results alternatively favor the river flow and precipitation control level.

Let us now consider the detectability of precipitation and river flow, one of the important properties for the evaluation of cloud seeding experiments. In the absence of information from existing literature, the detectability will be analyzed and discussed on an actual example. For this purpose, the Kings River Watershed above Piedra is selected again. The annual areal precipitation, $P_{i}$, for 14 water year period are related to the corresponding annual river flow of the Kings River at Piedra, $S_{j}$. Both $P_{i}$ and $S_{i}$, expressed in the same units as $P_{i}$, are given in Table 4. The data is graphically presented in Fig. 3, with the river flow being the dependent variable. Despite the scattering of points, which indicates that some effect of other variables is present, the trend of precipitation and river flow relationship is fairly definite. Drawing a straight line through the plotted points seems to be very acceptable for the observed range of variables. Therefore, the linear relation is defined mathematically as the least square line with river flow as a dependent variable where:

$$
S=b+c P \quad P_{\text {min }} \leq P \leq P_{\max } \cdot
$$

Forming the normal equations with the data from Table 4,

$$
\begin{aligned}
238.20 & =14 b+489.89 c \\
9446.60 & =489.89 b+18509.63 c,
\end{aligned}
$$

the coefficients $b$ and $c$, the S-intercept and the slope of the line respectively, are found to be:

$$
\begin{aligned}
& b=-11.47 \\
& c=0.814 .
\end{aligned}
$$

Hence, the linear precipitation and river flow relationship for the observed range is defined numerically as: 
Table 4. Annual areal precipitation and annual streamflow of the Kings River at Piedra, California

\begin{tabular}{|c|c|c|c|c|c|c|c|c|c|}
\hline Year & $\begin{array}{c}P_{i} \\
\text { (in. yr.) } \\
\end{array}$ & $P_{i}-\bar{P}$ & $\left(P_{i}-\bar{P}\right)^{2}$ & $\begin{array}{c}\mathrm{R} \\
\left(10^{3} \mathrm{ac}-\mathrm{ft} . / \mathrm{y}\right.\end{array}$ & $\stackrel{S_{i}}{(i n . / y r .)}$ & $S_{i}-\bar{S}$ & $\left(S_{i}-\bar{S}\right)^{2}$ & $P_{i} S_{i}$ & $\mathrm{P}_{i}^{2}$ \\
\hline 1951 & 39.07 & 4.08 & 16.65 & 1601.0 & 17.76 & 0.75 & 0.56 & 693.88 & 1526.46 \\
\hline 2 & 52.06 & 17.07 & 291.38 & 2856.0 & 31.80 & 14.79 & 218.74 & 1655.51 & 2710.24 \\
\hline 3 & 29.20 & -5.79 & 33.52 & 1155.0 & 12.84 & -4.17 & 17. 39 & 374.93 & 852.64 \\
\hline 4 & 33.47 & -1.52 & 2. 31 & 1339.0 & 14.88 & -2.13 & 4.54 & 498.03 & 1120.24 \\
\hline 1955 & 30.95 & -4.04 & 16.32 & 1143.0 & 12.72 & -4.29 & 18.40 & 393.68 & 957.90 \\
\hline 6 & 48.16 & 13.17 & 173.45 & 2695.0 & 30.00 & 12.99 & 168.74 & 1444.80 & 2319.39 \\
\hline 7 & 31.42 & -3.57 & 12.74 & 1259.0 & 14.04 & -2.97 & 8.82 & 441.14 & 987.22 \\
\hline 8 & 50.89 & 15.90 & 252.81 & 2615.0 & 29.04 & 12.03 & 144.72 & 1477.85 & 2589.79 \\
\hline 9 & 24.64 & -10.35 & 107.12 & 823.7 & 9.12 & -7.89 & 62.25 & 224.72 & 607.13 \\
\hline 1960 & 21.92 & -13.07 & 170.82 & 718.9 & 8.04 & -8.97 & 80.46 & 176.24 & 480.49 \\
\hline 1 & 22.28 & -12.71 & 161.54 & 571.5 & 6.36 & -10.65 & 113.42 & 141.70 & 496.40 \\
\hline 2 & 39.63 & 4.64 & 21.53 & 1871.8 & 20.76 & 3. 75 & 14.06 & 822.72 & $1570: 54$ \\
\hline 3 & 40.17 & 5.18 & 26.83 & 1902.0 & 21.12 & 4.11 & 16.89 & 848.39 & 1613.63 \\
\hline 1964 & 26.03 & -8.96 & 80.28 & 877.9 & 9.72 & -7.29 & 53.14 & 253.01 & 677.56 \\
\hline$\Sigma_{1}^{14}$ & 489.89 & & 1367.30 & 21428.8 & 238.20 & & 922.13 & 9446.60 & 18509.63 \\
\hline$\Sigma_{1}^{14} / 14$ & 34.99 & & 97.66 & 1530.6 & 17.01 & & 65.87 & & \\
\hline
\end{tabular}


$S($ in/yr)

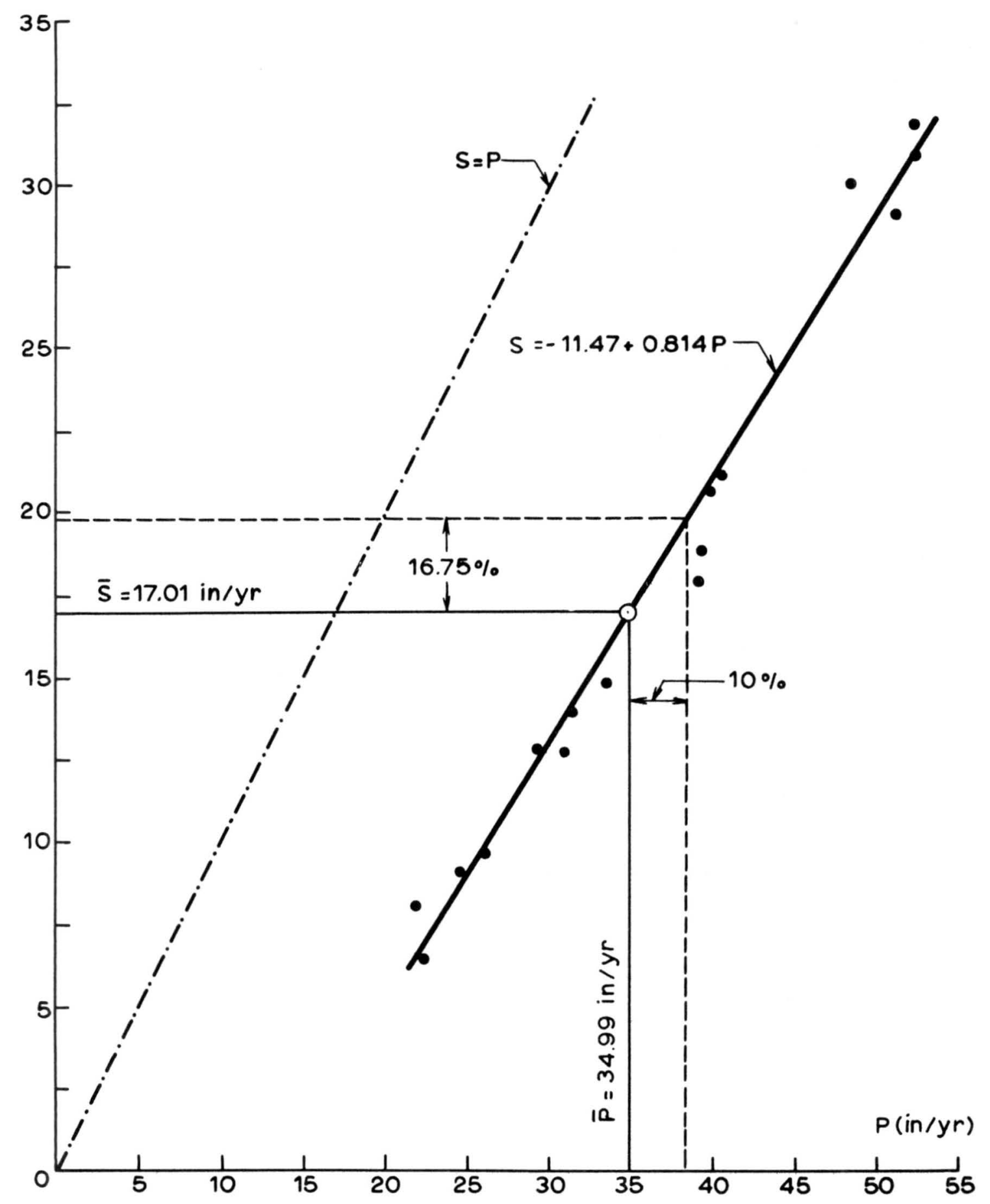

Fig. 3 Annual arcal precipitation and streamflow relationship for the Kings River Watershed above Piedra, California 


$$
S=11.47+0.814 P \quad 22 \leq P \leq 52
$$

Now, suppose that the Kings River Watershed has been seeded and that the average annual areal precipitation was increased by 10 percent, from 34.99 to $38.49 \mathrm{in} . / \mathrm{yr}$. due to the cloud seeding operations. Then, according to the above relationship, the average annual river flow would be:

$$
S=-11.47+0.814 \times 38.49=19.86 \mathrm{in} . / \mathrm{yr} .
$$

or it would be increased by

$$
\Delta S=\frac{(19.86-17.01) 100}{17.01}=16.75 \text { percent. }
$$

These two hypothetical increments are shown graphically in Fig. 3. This example well illustrates the superior sensitivity of river flow to that of precipitation. Thinking of river flow as a residual or the difference between the total precipitation over, and the total evapotranspiration from a watershed in a given time, any change in either of these would be magnified in the river flow. Thus, the detectability of the river flow control level is expected to be considerably higher than that of the precipitation control level.

To summarize, the river flow control level refers to the ground and measures directly and completely the water from a catching area available for man's use. It is a more accurate, reliable and detectable way of control than the precipitation control level.

A joint use of two or three control levels though possible, is not treated here. This is because of the unfavorable properties of the cloud phenomena and precipitation levels of control with respect to quantitative evaluation of weather modification experiments. A joint use of precipitation and river flow control levels in evaluating the weather modification attainments, with proper statistical techniques that may be developed and used, is an attractive idea which needs further research. That approach is beyond the objectives of this paper. 
6. CONCLUSIONS

Three possible control levels for quantitative evaluation of weather modification attainments were considered. As a result of this consideration, the following conclusions have been drawn:

(1) The cloud phenomena level of control is suitable for qualitative (physical) rather than for quantitative (statistical) evaluation of weather modification attainments.

(2) The precipitation level of control may be used for both qualitative and quantitative evaluations. However, the inaccuracy involved in single measurements of precipitation under different environmental conditions and in the determination of mean areal precipitation makes this level of control unreliable for the quantitative evaluation of weather modification attainments at the present time.

(3) The river flow control level has been shown suitable and promising, accurate and reliable for practical purposes, superior to the other two levels of control, and is, therefore, highly recommended for use in the quantitative evaluation of weather modification attainments. 


\section{BIBL IOGRAPHY}

1. Select Committee on National Water Resources, Water resources activities in the United States - Weather Modification. Washington, U. S. Government Printing Office, 1960, 46 p.

2. Final report of the Advisory Committee on Weather Control. Washington, Government Printing Office, 1958, Vol. I, 32 p.

3. Markovic, R. D., Evaluation of weather modification attainments by analysis of streamflow responses. Unpublished Ph. D. dissertation. Colorado State University, Fort Collins, Colorado, 1966, 157 p.

4. Braham, R. R., Cumulus cloud precipitation as revealed by radar. Arizona 1955. Journal of Meteorology, 1958, Vol. 15, No. 1, pp. 78-83.

5. Butler, S. S., Engineering Hydrology. Englewood Cliffs, Prentice Ha11, Inc., 1957, 356 p.

6. Linsley, R. K., Kohler, M. A., and Paulhus, J. L. H., Applied Hydrology. New York, McGraw-Hi11 Book Company, Inc., 1949, 689 p.

7. McGuinness, J.L., Accuracy of estimating watershed mean rainfall. Journal of Geophysical Research, 1963, Vol. 68, No. 16, pp. 4763-4767.

8. Linsley, R. K., and Kohler, M. A., Variations in storm rainfall over sma11 areas. Transactions of the American Geophysical Union, 1951, Vol. 32, No. 2, pp. 246-250. 